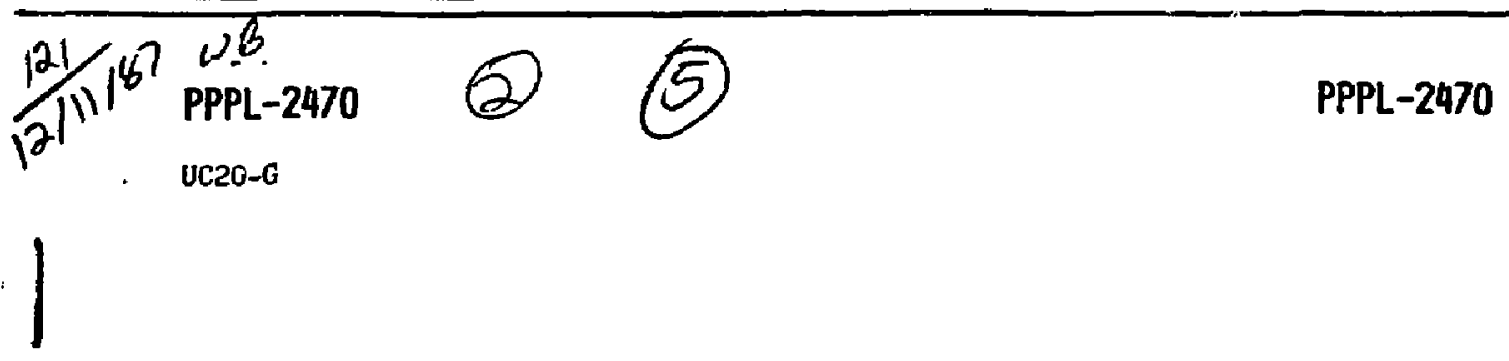

NEOCLASSICAL DIEFUSION OF HEAVY IMPURITIES IN A ROTATING \title{
TOKAMAK PLASMA
}

1 TOKAMAK

By

K.L. Wong and C.z. Cheng

\section{PLASMA PHYSICS \\ LABORATORY}

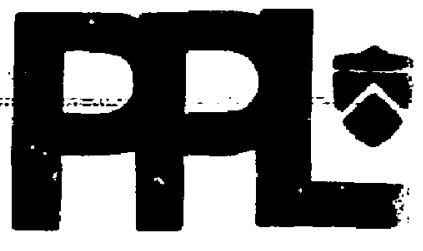

\section{PRINCETON UNIVERSITY}

FRINCETON, NEW JERSEY

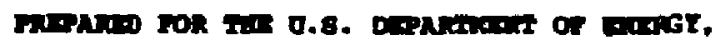

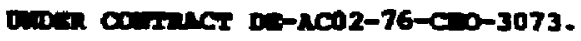


NEOCLASSICAL DIFEUSION OF HEAVY IMPURITIES IN A

ROTATING TOKAMAK PLASMA

\author{
K. L. Wong and C. Z. Cheng \\ Princeton Plasma Physics Laboratory \\ Princeton, New Jersey 08544
}

PPPL -2470

DE88 003463

\begin{abstract}
Particle orbits in a rotating tokamak plasma are calculated from the equation of motion in the frame that rotates with the plasma. It is found that heavy particles in a rotating plasma can drift away from magnetic surfaces significantly faster, resulting in a diffusion coefficient much larger than that for a stationary plasma. Particle simulation is carried out and the results offer a qualitative explanation for some experimental data from the Tokamak Eusion Test Reactor (TFTR).
\end{abstract}

\title{
DISCLAIMER
}

This repon was prepared as an account of work sponsored by an agency of the United States employees, makes any warranty, States Government nor any agency thereof, nor any of their bility for the accuracy, completeness, or usefulied, or assumes any legal liability or responsiprocess disclosed, or represents that its use would of any information, apparatus, product, or ence herein to any specific commercial product, proats infringe privately owned rights. Refermanufacturer, or otherwise does not necessatily const, or service by trade name, trademark, mendation, or favoring by the United States Government or imply its endorsement, recom. and opinions of authors expressed herein do not necessarily stagency thereof. The views United States Government or any agency thercof. necessarily state or reflect those of the 
Existing theories ${ }^{1,2}$ predict that impurity transport can be altered by an external momentum source, like neutral bear injection. Co-injection produces outward impurity convection and counter injection produces inward convection. Although experimental evidence of such impurity behavior was reported in the ISX-B tokamak experiment, ${ }^{3}$ inpurity injection experiments on the Princeton Large Torus (PLT) ${ }^{4}$ showed no significant difference in impurity transport with so- or counter-beams because the temporal evolutions of impurity line radiation were quite similar in both cases. The only noticeable difference was in the amount of impurity penetrating into the plasma interior. With the same injected amount, the impurity concentration in the core plasna with counter-beams was two to three times higher than that with co-beams. Similar results have been obtained recently from TFTR. 5 It is found that diffusion plays an important role in impurity transport. Therefore, it is important to calculate the effect of plasma rotation on impurity diffusion. In this paper, we calculate the orbits of impurity ions in a rotating plasna and determine the neoclassical diffusion coefficient $D_{\text {neo. }}$. We discover that $D_{\text {neo }}$ for heavy impurities can be one to two order of magnitude higher in a rotating plasma than in a stationary one, and our calculations agree qualitatively with some TFTR experimental data. 5

Let us assume concentric circular magnetic surfaces which rotate as rigid shells about the axis of symmetry with angular frequency $w(r)$. We choose a toroidal coordinate system which rotates with the plasma so that the magnetic fleld lines are stationary. The equation of motion for a charged particle with charge number $Z$ in a rotating frame is:

$$
\text { m } \frac{d \vec{v}}{d t}=2 e(\vec{E}+\vec{v} \times \vec{B})-2 m \vec{\omega} \times \vec{v}-m \vec{\omega} \times\left[\vec{\omega} \times\left(\vec{R}_{0}+\vec{r}\right)\right] \text {. }
$$


$\mathrm{R}_{\mathrm{o}}$ is the plasma major radius and the last two terms on the right hand side of Eq. (1) are the Coriolis force and the centrifugal force. We assume that the bulk plasma consists of electrons and a single ion species of mass $m_{i}$ and charge number $z_{i}$. We put $z_{i}$ equal to the plasma effective ion charge number $z_{\text {eff }}$ and $m_{i}=2 z_{\text {eff }} m_{p}$ where $m_{p}$ is the proton mass. The impurity ions with mass $m_{I}$ and charge number $z_{I}$ are assumed to be in the "trace Iimit," such that their presence causes negligible changes in $z_{\text {eff }}$ and other plasma parameters. He know that the magnetic surface is approximately an equipotential surface, so that $\varphi=\varphi_{0}(r)$. In a rotating plasma, the ions are pushed towards the large-major-radius side by the centrifugal force. An electrostatic potential $\Phi_{1}$ is set up to maintain charge neutrality: 6

$$
\Phi_{1}=\frac{\omega^{2}}{2} \frac{m_{i}}{e} \frac{T_{e}}{T_{i}+2_{i} T_{e}}\left(R^{2}-\left\langle R^{2}\right\rangle\right) \text {, }
$$

where < > denotes averaging over the magnetic surface. It has been shown ${ }^{7}$ that the magnetic moment $\mu=1 / 2 m_{I} v_{1}^{2} / B$ and the particle energy are adiabatic invariants in the rotating frame. Let $R_{1}$ and $R_{2}$ be the maximum and minimum of $R$ on a flux surface. Impurlty ions at $R=R_{1}$ are trapped if

$$
\frac{1}{2} m_{I}\left[v_{1}^{2}-\left(\frac{R_{1}}{R_{2}}-1\right) v_{1}^{2}\right] \leq \frac{1}{2} m_{I} \omega^{2}\left(R_{1}{ }^{2}-R_{2}^{2}\right)+z_{I} e\left[\Phi\left(R_{2}\right)-\Phi\left(R_{1}\right)\right] .
$$

The boundary between trapped and untrapped particles in velocity space is a hyperbolic surface defined by Eq. (3) with the equal sign. Nearly all the heavy impurity ions are trapped when a plasma is rotating at high velocity like the energetic ion mode plasma in TFTR, ${ }^{8}$ which is characterized by low density and high ion temperature with high co-infecting neutral beam power. 
Equation (1) can be solved by using the guiding center approximation. The guiding center orift velocity is:

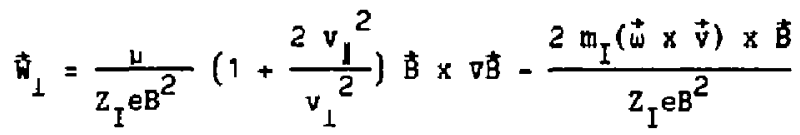

$$
\begin{aligned}
& -\frac{m_{I}\left[\vec{\omega} \times\left(\vec{\omega} \times\left(\vec{R}_{0}+\vec{r}\right)\right\}\right] \times \vec{B}}{z_{I} e \theta^{2}}+\frac{\vec{E} \times \vec{B}}{B^{2}},
\end{aligned}
$$

where $\vec{E}=-\nabla\left(\theta_{0}+\theta_{1}\right)$. Guiding center orbits can be obtained by integrating Eq. (4) together with the parallel component of Eq. (1). For typical energetic-ion mode plasmas in TFTR, the banana widths of impurity ion orbits are about a few centimeters, which is only a small fraction of the minor radius $(82 \mathrm{~cm})$. Therefore, it is a reasonably good approximation to neglect the variation of $\omega(r)$ along the particle orbit. For a more accurate treatment, variation of $w(r)$ can be accounted for by adding a radial electric field which can be absorbed into $0_{0}(r)$. The orbit characteristics are sensitive to the direction of rotation. It offers a qualitative explanation for the observation of higher impurity concentration in rotating plasmas with counter-beams. 9

The neoclassical diffusion coeffictent of the impurity ions can be calculated from the radial component of the drift velocity as follows:

$$
D_{n e 0}=\tau_{\tau} \lim _{\infty} \frac{(\Delta r)^{2}}{2 \tau}=\lim _{\tau} \frac{1}{2 \tau} \int_{0}^{\tau} d t \int_{0}^{\tau} d t^{\prime} W_{r}(t) W_{r}\left(t^{\prime}\right)
$$

Consider particles doing a random walk ${ }^{10^{\circ}}$ along magnetic field lines. If the collisional mean-free-path is much less than the plasma major radius, the impurity distribution function is locally Maxwellian with a temperature $T_{I}$, the same as the bulk ion temperature. Equation (5) can then be evaluated to yield 


$$
\begin{aligned}
D_{\text {neo }} & =\frac{1}{4}\left(\frac{m_{I}}{z_{I}{ }^{e B}}\right)^{2}\left[\omega^{4} R^{2}\left(1-\frac{m_{i}}{m_{I}} \frac{z_{I} T_{e}}{T_{i}+z_{i} T_{e}}\right)^{2}\right. \\
& \left.+\omega^{2}\left(1-\frac{m_{i}}{m_{I}} \frac{Z_{I} T_{e}}{T_{i}+z_{i} T_{e}}\right) \frac{4 T_{i}}{m_{I}}+\frac{4 T_{1}^{2}}{m_{I}{ }^{2} R^{2}}\right] \frac{m_{I}{ }^{v}}{T_{i}} R^{2} q^{2},
\end{aligned}
$$

where $v$ is the impurity ion collision frequency and $q$ is the safety factor. In a stationary plasma, $w=0$ and Eq. (6) is reduced to the same result as obtained by Galeer and Sagdeev. "11 When $\mathrm{m}_{I} \omega^{2} \mathrm{R}^{2} \gg \mathrm{T}_{1}$, the diffusion coefficient becones much larger. It is interesting to note that Eq. (6) depends on even powers of which means that in the highly collisional regime, the diffusion coefficient is independent of the direction of plasma rotation.

The above result applies only to impurity lons in the Pfirsh-Schlater regime. In the TFTh energetic-ion mode plasma, impurity fons are collisional only at the edge; they are mildly collisionless near the plasma core. A 3-D particle simulation code ${ }^{12}$ is used to calculate the neoclassical diffusion coefficient. The code follows the impurity guiding center positions with drift velocities given by $\mathrm{Eq}$. (4). Pitch angle scattering is modeled by a Monte-Carlo collision operator. 13 Thermal equilibration between impurity ions and the bulk plasma is also included. At $t=0,1024$ impurity particles are distributed uniformly on a flux surface with $T_{I}=T_{1}$. The difrusion coefficient is calculated from $D_{\text {neo }}=\left\langle(\Delta r)^{2}\right\rangle_{p} / 2 t$ where $\Delta r$ is the excursion of a particle from the original flux surface and < > denotes averaging over all the particles. In order to compare with experiments in TFTR, we choose germanium as the impurity species. The charge number $z_{I}$ is determined by the local electron temperature and the lonization potential $\varphi_{I}(z): \quad z_{I}=Z$ if ${ }_{I}(Z)<T_{e} \leq \oplus_{I}(Z+1)$. Lorentzian plasma perameter profiles are used for computational conventence: $n_{e}(r)=n_{e}(0) /\left(1+4 r^{2} / a^{2}\right), T_{e}(r)=T_{e}(0) /(1+$ 
$\left.9 r^{2} / a^{2}\right), T_{1}(r)=T_{1}(0) /\left(1+9 r^{2} / a^{2}\right), \omega(r)=\omega(0) /\left(1+4 r^{2} / a^{2}\right), B_{T}=40$ $k G$. He put the zeroth order radial electric fleld to be $E_{r}=400 / 11+17$ $\left.r^{2} / a^{2}\right)$ volts/m, and the safety factor to be $q(r)=1.1\left(1+6.5455 r^{2} / a^{2}\right)$ which corresponds to $I_{p}=700 \mathrm{kA}$. The central parameters are chosen to be similar to the experimental values: $n_{e^{(0)}}=2 \times 10^{13} \mathrm{~cm}^{-3}, T_{e}(0)=4 \mathrm{keV}, T_{i}(0)=10$ keV, $\omega(0)=2 \times 10^{5} \mathrm{rad} / \mathrm{sec}$. Figure 1 shows the evolution of the spatial distribution of the particle guiding centers. As the particles diffuse fron the original flux surface, they tend to move towards the large-major-radius side and become trapped after a few collisions. In a stationary plasma, we find that $\left\langle\Delta r^{2}\right\rangle_{p}$ increases linearly with time after many collisions. Dneo converges to a fixed value at $t \geq 8 \mathrm{~ms}$ at which the excursion from the original flux surface is still small (or $<<a$ ) for most of the particles, and the solid points in Fig. $2 a$ were taken at $8.2 \mathrm{~ms}$. In the rotating plasme, neoclassical diffusion is much faster so that $4 r \sim a / 2$ at $t-8 \mathrm{~ms}$, and the values of $D_{\text {neo }}$ were taken at $t=1.6 \mathrm{~ms}$ at which $\Delta \mathrm{r} \leq 0.1$ a for the majority of the particles. It is apparent that neoclassical diffusion is entanced by one to two orders of magnitudie due to plesma rotation. In a stationary plasma, $D_{n e o}$ is very small and impurity transport is governed by some anomalous processes. In a rotating plasma, $0_{\text {neo }}$ can be large enough to compete with anomalous transport and causes enhanced diffusion in impurity infection experiments. In fact, the values shown in Fig. $2 a$ are close to what is needed $\left(3 \times 10^{4} \mathrm{~cm}^{2} / \mathrm{sec}\right)$ to explain the experimental data from the TFTR tokamak.5 Quantitative comparison with experiment is not possible at this tiue due to the lack of profile data on w(r), $T_{1}(r)$ and $\rho_{0}(r)$. As an Independent check for the particle simulation results, we assume that all the Impurity ions are trapped and then estimate the diffision coefficient from $D=$ $v_{\text {eff }} \Delta_{b}^{2} ; \Delta_{b}$ is the banana width of a "typical" particle with $v_{1}=r T_{i} / m_{I}, v_{1}$ 
$=r 2 T_{i} / m_{I}$ at $\theta=0$, and $v_{e f f}=1.27 v_{90^{\circ}}$, is the collision frequency for $v_{H}$ to change sign. It should be noted that the trapping fraction is significantly less than unity near $r=0$, and the impurity ions are not in the banana regime near the plasma edge. Therefore, the triangular polnts in Fig. 2a can only be treated as an order-of-magnitude estinate; it is an overestinate at $r \sim a$, as well as at $r$ - 0 . Flgure $2 b$ shows the varlation of $D_{\text {neo }}$ with the plasma current at two different rotation velocities. The shape of current density profile and other plasma parameters remain the same. $D_{\text {neo }}$ is obtained by particle simulation at $r=a / 2$. The results show that $D_{\text {neo }}$ drops to a low value at high plastra current and low rotation velocity, at which we expect that impurity transport would be dominated by other anomalous processes. This also qualitatively agrees with the observations reported prevlously, 5

In surmary, we have shown that neoclassical diffusion of heavy impurity ions can be much larger in a rotating plasma because of the enhanced drift velocity. Particle simulation results are in qualitative agreement with some experimental data from TFTh.

\section{ACKNOHLEDGMENTS}

The authors would like to thank Drs. S. Cowley, R J. Goldston, R. J. Hawryluk, K. Hill, H. Hsuan, R. Hulse, A. Ramsey, J. Strachan, B. Stratton, S. Suckewer, S, von Goeler, and H. Zarnstorff for many helpful discussions.

This work is supported by U.S. Department of Energy Contract No. DE-ACO276-CH03073. 


\section{REFERENCES}

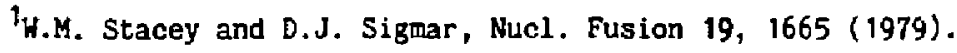

${ }^{2}$ K.H. Burre11, T. Ohkawa and S.K. Hong, Phys. Rev. Lett. 47, 511 (1981).

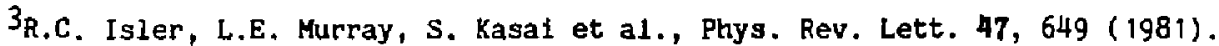

4s. Suckewer et al., Nucl. Fusion 24, 815 (1984).

5B.C. Stratton, S.A. Cohen et al., J. Nucl. Mater. 145-147, 582 (1987).

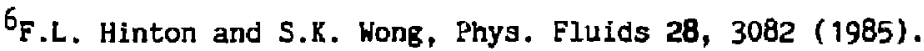

7S.C. Cowiey and C.M. Bishop, Culham Laboratory Report CLM-M109, Abingdon, Oxfordshire, 1986.

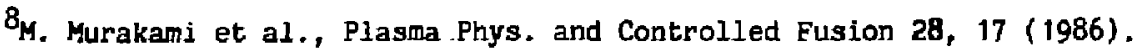

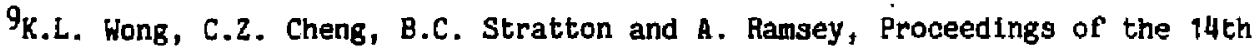
European Conference on Controlled Fusion and Plasma Heating, (Madrid, Spain) June 22-26, 1987, paper A-20.

10. Chandrasekhar, Rev. Mod. Phys. 15, 3 (1943).

${ }^{1}$ A.A. Galeev and R.Z. Sagdeev, Sov. Phys. JETP 26, 233 (1968).

${ }^{12}$ C.2. Cheng and H. Okuda, J. Comp. Phys. 25, 133 (1977).

13R. Shanny, J.M. Dawson and J.M. Greene, Phys. Fluids 10, 1281 (1967). 
Figure Captions

Fig. 1 Temporal evolution of impurity guiding center distributions in a rotating plasma at (a) $t=0,(b) t=0.66 \mathrm{~ms}$, and $(c) t=3.28 \mathrm{~ms}$.

Fig. 2 (a) Calculated diffusion coefficients at various ratial locations with $\omega(0)=2 \times 10^{5} \mathrm{rad} / \mathrm{sec}$ and $\omega(0)=0$.

(b) Varlation of diffusion coefficient (at $r=a / 2$ ) with plasma current at two rotation velocities. 

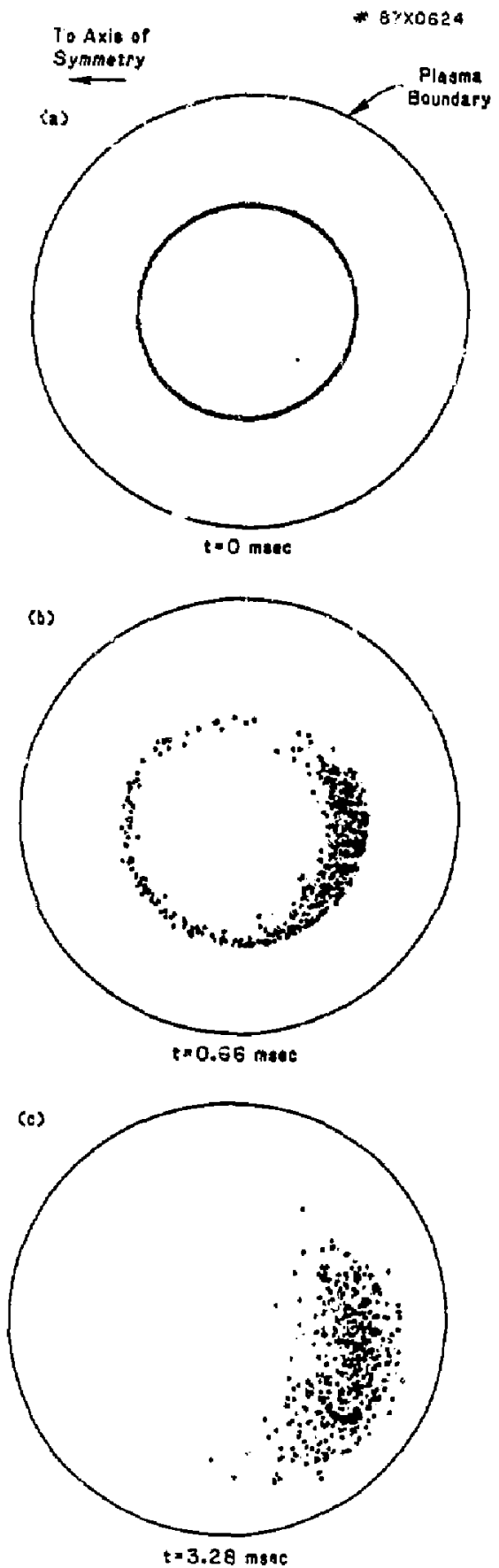

Fig. 1 

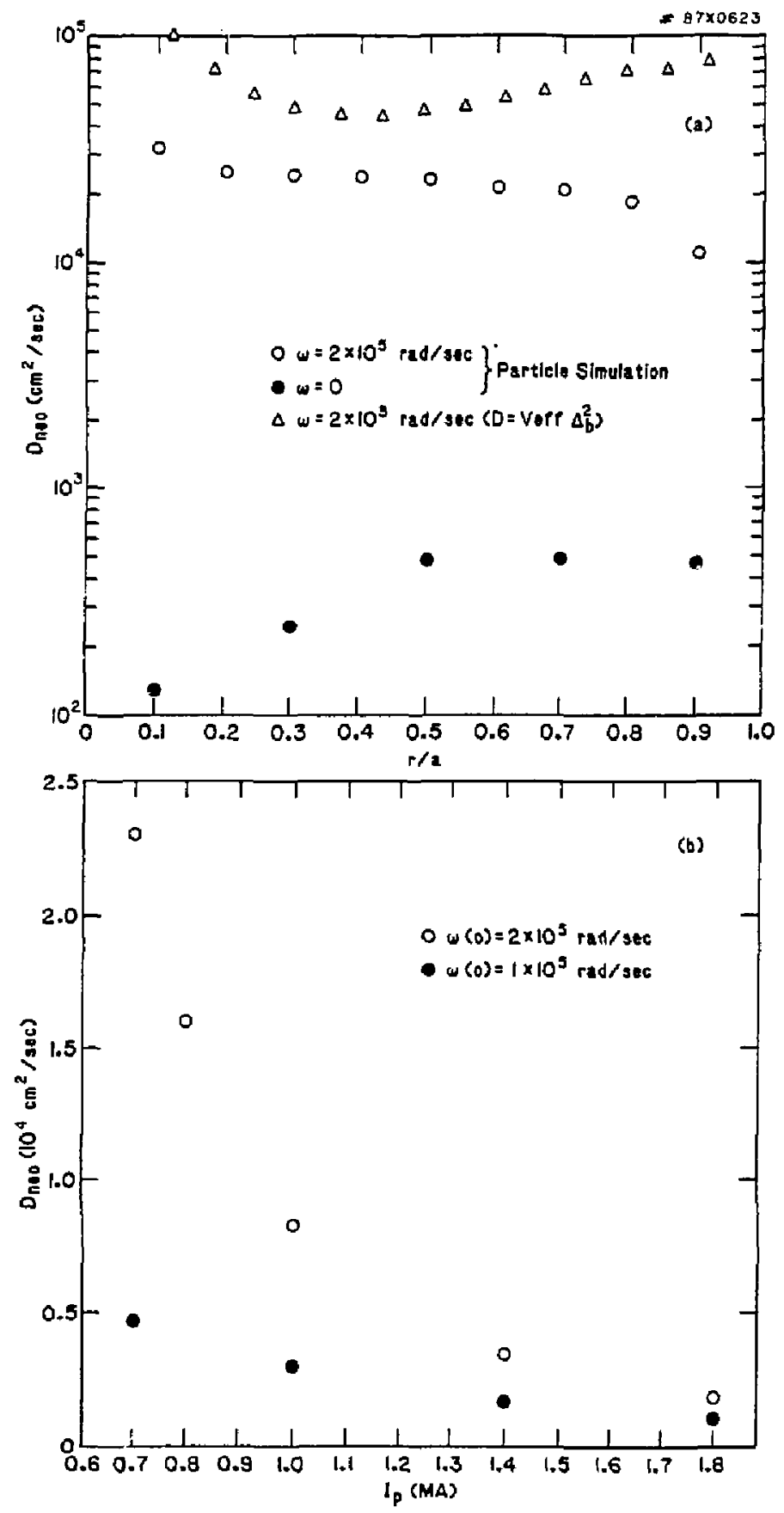

Fig. 2 
Dr. Frank J. Paolonl, Unir of Wollongong, AustRALIA Prot. M.H. Bronnan, Univ Syanoy, AUSTRALIA Plasme Research Lab., Australian Nat, UnlV., AUSTRALIA Prot. I.R. Jones, FIInders Univ., NSTRALIA Prot. F. Cap, inst Theo Phrs d MSTRI Prot. M. Holndier, Institut fur Theoretisehe Physik, MUSTRI. M. Goossens, Astronowisch Instituut, EELGIUA Ecole Royale MIlltalro, Lob do Phys Plasms, BELGila Com, of Europeon, Dg Xit Fusion Prog, BELGIUM Prof. R. Bouclque, Laboratorlum voor Nafuurkurisu, BELGiu Or. P+H. Sokenoka, Unir Estadual, ERAZIL Instituto De Pesquisas Espaclas I-INPE, BRAZIL Library, htomls Energy of canede Limited, CAMNOA Dr. M.P. Bachynskl, MPB Tochnologles, InE., CNAOA Dr. H.M. Skarsgard, UnIY of Saskatemevan, CANADA Dr. H. Barnard, University of British COlunbla, CAHADA Prof. J. Tolchmann, Univ. of Montral, CANKOA Prof. S.R. Sreanlvasan, linlversity of Calgary, CNMAN Prof. Tudor W. Johnston, ImS-Enargle, CNHOA Dr. C.R. Jnows, UnlY, of Alberta, CANAOA Dr. Pater Lukec, Komenskeno Univ, CZECroslovakia The Llbrartion, Culhes Laboratory, ENGLAwD Mrs. S,A. Hutehinson, JET LIbrary, EKGLARD C. Wouttht, Lob. do Physique das Milleux lonlsés, fRnuct J. Radet, CEN/CNOAnNCHE - Bat 306, FRANCE

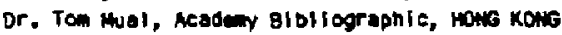
Preprtint Llorory, Cent Res Inst Phys, HUWARY Dr. B. Dasegupta, Saho Inst, INDIA Dr. R.K. Chhajlanl, Yikrem UnIY. IhDiA Or. P. Kew, Institute for plase Rereareh, INDIA Or. Pnilltp Rosensu, Isreal Inst Tech, ISRAEL Prof. S. Cuperman, Tel AuIv Untversity, ISRAEL LIbrarlan, Int'l Ctr thwo Phys, ITALY Prot. G. Rostagal, UnIv DI Podove. ITALY MIss Clat la Do Palo, Assoc ELRATO-ENEA, !TALY Blbllotece, del ONR EURATON, ITALY

Dr. H. Yomato, Tasnibe Res 4 Dov, JAPAN

Prof. 1. Kowakeal, Atomic Enargy Ros. Institute, JAPAN

Prof. Kyoj1 MIsnikewe, UnIV of HIroshles, JAPAM

olroc. OegT, Lg, Tokank Ras, JAERI, JPAN

Prot. Satoshl Itoh, Kyushu University, JAPN Research info Center, Magiya University, JAPNH Prof. S. Tanake, Kyoto University, JAPAN Library. Kyoto unlverslty, Japh Prot. Mobuyukl inoue, Univeraliy of Tokyo, JAPN S. Mori, JAERI, JAPAY M.H. Kin, Korea Advaneed Energy Research Inatltute, KOREA Prat. D.1. Chol, Adr. Inst Sal \& Tech, KOREA Prof. B.S. LIIE, Univarglty of Walkate, NEW ZEMLAND institute of Plose Physlcs, PEOple's Revulic of CHIM Llbrarlan, Institute of Phys., PEOPLE'S REUULL IC Of CHINA Library, Tsing the University, PECPLE's REPUBLIC or CHIM
2. Li. Southwest Inst. Physies, fEOPLE'S RePUBLIC Of CHINA Prot. J.A.C. Cabral, Inst Suparlor Teen, PORTUGAL Or. Octarlan Petrus, AL I CUZA UnIvarsity, ROMANIA Or. Johan de villlers, Plasm Physles, AEC, SO AFRICA Prot. M.A. Hellberg, University of Natal, SO AFRICA Fusion DIr. Library, JEN, SPAIN

Or. Lennert Stenflo, Unlversity of LHEA, SHEDEN Library, Royal inst Tech, JWEDEN

Prof. Hons Wilhelmon, Chaimars Univ Tach, SWEDEN Centre Phys des Plasmas, Ecole Polytech Fed, SwITzERLAND Gibllothew, Fom-l int Yoor Plasma-Fyslca, THE NETHERLAMDS Dr. O.D. Ryutov, SIberlan Acad Sel, USSR

Dr. G.A. Ell sew, Kurchatov institute, USSR

Dr. $V_{*}$, Glukhikh, Inst Electro-physical, USSR

Dr. V.T. Tolok, Inat. Phys. Toch. USSR

Dr. L.M. Kovrlizhnykh, Institute Gen. Physlcs, Ussa rrot. T.S.H. Boyd, Univ College N Wales, WALES Nuclear Res. Establi ishment, Jullich LTd., H. GERWWY Bl bllothak, Inst. Fur Plosatorsenung, H. GERMAYY Or. K. Schlndler, Ruhr Unlversitet, W. GERuwY AFOEX Reading Pin, IPP/Max-Plenek-Institut fur

Plasmaphyslk, W. GEpakr

Lltrarian, Mxtianck institut, W. GeRouwr

Prov. R,K. Janev, Inst Phys, Yueoslayia

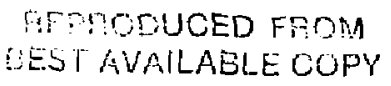

